\title{
Enhancement of Impinging Jet Heat Transfer Using Two Parallel Confining Plates Mounted near Rectangular Nozzle Exit
}

\author{
Yoshiaki Haneda, ${ }^{1}$ Akiko Souma, ${ }^{1}$ Hideo Kurasawa, ${ }^{1}$ Shouichiro Iio, ${ }^{2}$ and Toshihiko Ikeda ${ }^{2}$ \\ ${ }^{1}$ Nagano National College of Technology, Nagano 381-8550, Japan \\ ${ }^{2}$ Shinshu University, Nagano 380-8553, Japan \\ Correspondence should be addressed to Yoshiaki Haneda; haneda@nagano-nct.ac.jp
}

Received 1 October 2013; Accepted 16 January 2014; Published 25 March 2014

Academic Editor: Toshiyuki Gotoh

Copyright (C) 2014 Yoshiaki Haneda et al. This is an open access article distributed under the Creative Commons Attribution License, which permits unrestricted use, distribution, and reproduction in any medium, provided the original work is properly cited.

Impinging jet heat transfer on a target plate was enhanced by using two parallel confining plates mounted between a rectangular nozzle end plate and a jet target plate. The target plate was set equal to $2,3,4$, and 5 times the jet exit width, $h$, and the gap ratio of two parallel confining plates, $W / h$, were changed from 2.7 to 8.0 only by impinging length $H=5 h$ and from 2.7 to 6.7 by $H \neq 5 h$. Two confining parallel plates mounted near the jet exit produced swing-type flow under some conditions. As a result, the maximum Nusselt number attained around the stagnation point was augmented by about $50 \%$ compared to the one for normal impinging jet without the two parallel plates and then spatial mean Nusselt number was increased by about $40 \%$.

\section{Introduction}

Impinging jets have been used in several industrial processes, for example, for cooling of steel, glass, electronic components, and gas turbine vanes, for drying of paper, film, and textiles, and for freezing food and tissue in cryosurgery, because the high heat and mass transfer coefficients can be obtained around a jet stagnation region and the heat transfer characteristics can be easily controlled. In the meantime, Deo et al. [1] have examined characteristics of turbulent jets issuing from rectangular nozzles with and without two parallel plates attached as sidewalls to the slot's short sides. They reported that the potential core of the jet without sidewalls was shorter than that with sidewalls and the centerline turbulence intensity of the jet with sidewalls became asymptotical closer to the nozzle exit than that of the jet without sidewalls. The results suggest that a characteristic of impinging jet heat transfer on a target plate with sidewalls is different from that without sidewalls.

By the way, jets often impinge onto a target body mounted in confined spaces for manufacturing processes of frozen food and heat treatment of electronic components, and so forth. San et al. [2] and Lin et al. [3] have studied heat transfer on a surface for mounting an end plate flush with a jet exit. Gao and Ewing [4] have examined static and fluctuating wall pressure and heat transfer on a surface for unconfined jets and confined jets with an end plate. They found that the location of the decrease in the heat transfer and the fluctuating wall pressure in the confined jets shifted laterally outward as a nozzle-to-plate distance increased. Fitzgerald and Garimella [5] have studied characteristics of the flow field of an axisymmetric, confined, and submerged turbulent jet impinging normally on a flat plate experimentally. They mapped the toroidal recirculation pattern in the outflow region characteristic of confined jets with an end plate. Fenot et al. [6] have showed the independence of heat transfer coefficients and effectiveness from a jet injection temperature for confined and unconfined jets. The results showed that the influence of confinement was weak, but it had a great impact on effectiveness. More recently, San and Shiao [7] have examined the effects of jet plate size and plate spacing for mounting removable bars between an end plate mounted flush with a jet exit and a target plate on the heat transfer characteristics for a confined circular air jet 


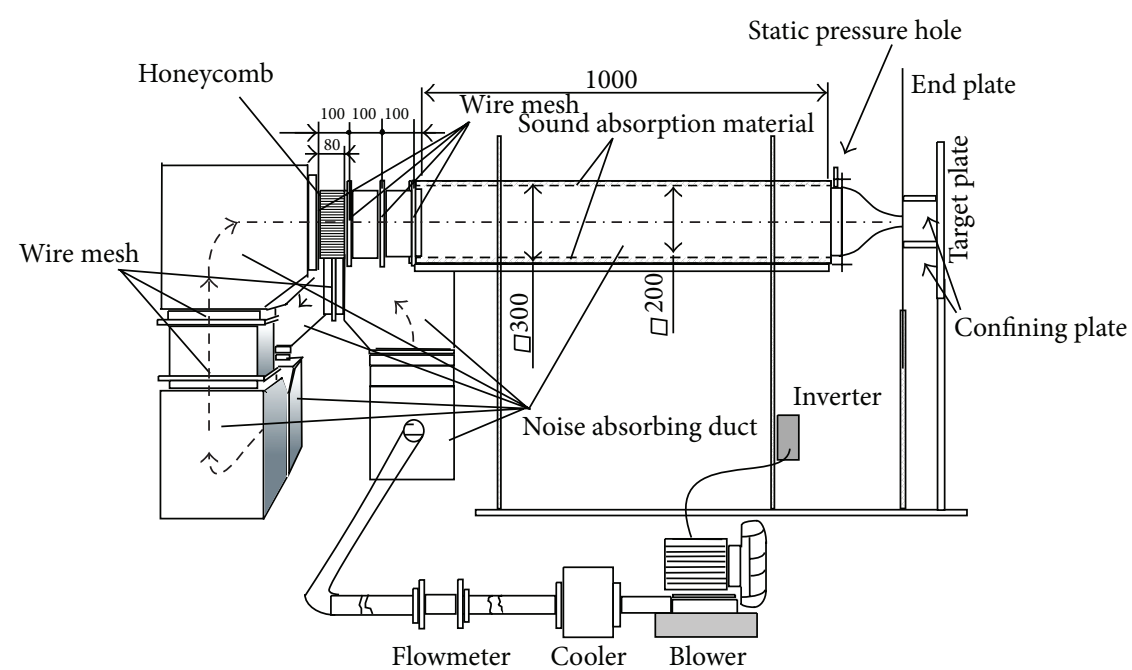

(a)

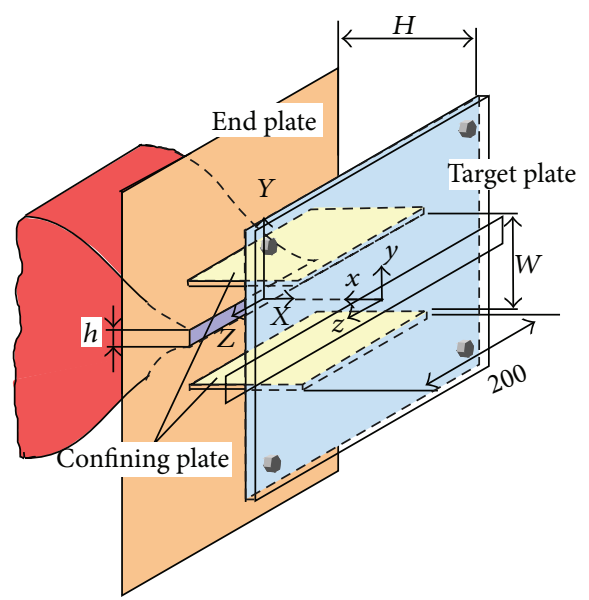

(b)

FIGURE 1: Schematic illustrations of experimental setup and the coordinate systems.

vertically impinging on a flat plate. They showed the effects of the jet plate width-to-jet diameter ratio on the stagnation Nusselt number. In addition, San et al. [8] have also studied impingement heat transfer of staggered arrays of air jets confined with an end plate and the removable bars.

Yet, up to date, there have been few investigations concerning heat transfer of a rectangular impinging jet confined with an end plate, target plate, and two confining plates mounted in parallel with long sides of the rectangular nozzle exit. The objective of this work is to examine the flow field and heat transfer influenced by two parallel plates mounted near a rectangular nozzle exit. Measurements of the heat transfer and fluctuating pressure on a target plate were performed for the impinging jet with nozzle-to-target plate distances and with confining plate-to-plate distances. Flow field for the impinging jet was qualitatively visualized using a smoke-wire method and smoke method. The experimental facilities used in this study are presented in the next section. The results of experiments are then presented and discussed. Finally, the conclusions obtained here are presented.

\section{Experimental Apparatus and Procedure}

Figure 1 shows schematic illustration of experimental setup and the coordinate system. The facility used to produce a jet consisted of a blower, a cooler for maintaining the air temperature within $2^{\circ} \mathrm{C}$ of an ambient temperature, an orifice flow meter, pipes made from polyvinyl chloride, some noise absorbing ducts, and a contraction. A honeycomb of length $80 \mathrm{~mm}$ with hexagon cells of $4 \mathrm{~mm}$ and wire meshes were installed in the connection part of the ducts for rectification. The nozzle contraction had an area ratio of about $13.3: 1$ and employs a smooth contraction profile based on sine curve and following the curve had parallel section with the length of $10 \mathrm{~mm}$ connecting to the exit to enhance flow uniformity. A rectangular nozzle exit contracted had a cross-section area with the length of $200 \mathrm{~mm}$ and the width, $h$, of $15 \mathrm{~mm}$, whose outlet rim was arranged flush mount with an end plate. The jet issuing horizontally through the exit impinged onto a target plate perpendicularly mounted in the middle plane of the jet. The nozzle-to-target plate spacing, $H$, was set equal to $H / h=2,3,4$, and 5 , where those places corresponded to a potential core region of the free jet used in the present study. Two parallel confining plates having the length of $200 \mathrm{~mm}$, whose length and width were equal to the length of the nozzle exit and the $H$ value, respectively, were mounted between the end plate and the target plate for each position, $H$. The spacing between the two confining plates mounted in parallel with the long sides of the exit, $W$, was set equal to $W / h=$ 2.7, 3.3, 4, 5.3, and 6.7 for $H / h=2,3$ and 4 and to 2.7, 3.3, $4,5.3,6.7$, and 8 for $H / h=5$ only. The intersection between the geometric jet central axis and a target plate was defined as the origin of coordinate, and the $z$ axis was taken across the length of the jet exit from the origin.

For the measurements of pressure and heat transfer on the target plate, the jet exit velocity obtained from flow rate divided by the cross-section area of the nozzle exit was set at $10 \mathrm{~m} / \mathrm{s}$, resulting in a Reynolds number, Re, based on the nozzle width, $h$, and kinematic viscosity, $v$, of about 9500 . For only flow visualization using a smoke-wire method, the velocity was set at $5 \mathrm{~m} / \mathrm{s}$ to obtain good quality pictures of the flow field. The adjustment of the flow rate was carried out by changing the rotational frequency of the blower with an inverter. The flow rate was almost constant without the adjustment of its rotational frequency in all cases, even if the confining plate-to-plate spacing and the nozzle exit-to-target plate distance changed.

The target plate for the measurements of fluctuating pressure on the surface consisted of three pieces as shown in Figure 2. The middle sliding plate was manually traversed along the $z$ direction within the region $-8 \leq z / h \leq 8$. A small pressure hole with $0.5 \mathrm{~mm}$ in diameter and $5 \mathrm{~mm}$ in depth 


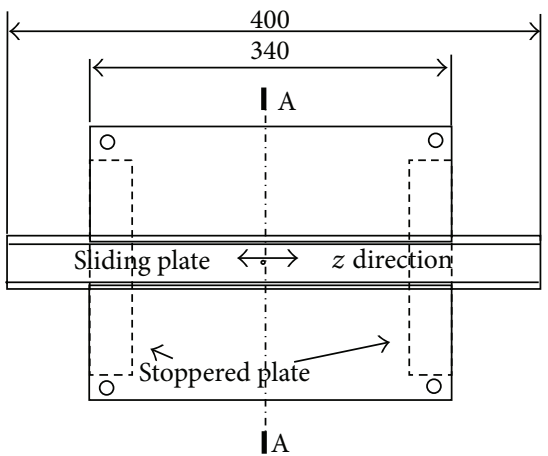

(a)

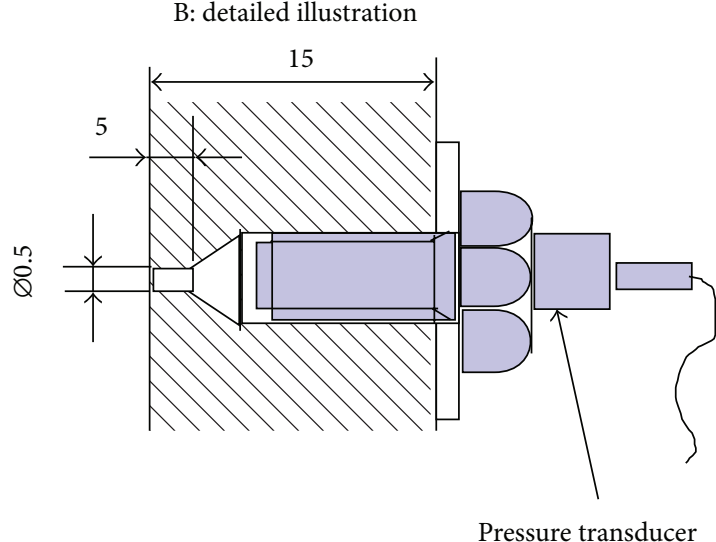

(b)

FIGURE 2: Target plate used in the pressure measurement.

was drilled from the front surface at its geometrical center and a differential pressure transducer used in measurement of the pressure was screwed into a blind hole drilled into the wall to the small hole. The transducer output signal was amplified using a strain amplifier module. The voltage signals from the amplifier were recorded onto a data logger in 30,000 data points at a frequency of $5,000 \mathrm{~Hz}$. Time averaged mean pressure and root mean square values of the fluctuating pressure were calculated from the data recorded with a personal computer. The pressure on the target plate was measured at $5 \mathrm{~mm}$ interval by traversing the sliding plate within the region $-8 \leq z / h \leq 8$.

The smoke wire method was used for the visualization of confined flow field. The smoke wire was consisted of two nichrome wires with $50 \mu \mathrm{m}$ in diameter, which were uniformly twisted together. It was individually placed at the center of the nozzle exit and a little downstream along the $y$ axis. It was coated by paraffin oil before each test and heated by impulse direct current. Pictures of the resultant white streak lines were taken using digital camera and stroboscope light. Additional flow visualization was conducted: oil mist generated from a smoke generator was absorbed to the blower and the oil mist gushed out of the nozzle was observed with a video camera.

For the measurements of local heat transfer, three stainless steel strips $20 \mu \mathrm{m}$ thick, $8 \mathrm{~mm}$ wide, and $260 \mathrm{~mm}$ long were glued in parallel with each other along the $z$-direction. These strips were electrically connected in series and were heated by passing alternating electric current. Distribution of the heated surface temperature was measured with 49 thermocouples allocated to contact with the back surface of the central strip at $5 \mathrm{~mm}$ interval so as to cover the region from $z / h=-8$ to $z / h=8$. Heat flux was basically uniform but correction was carried out for its nonuniformity produced by the conductive loss toward the back surface of the target plate on which glass wool with $20 \mathrm{~mm}$ in thickness was mounted. The radiative heat loss to the ambient was neglected as the radiative heat loss was evaluated to be less than $3 \%$ of the total heat flux. Thus, Local Nusselt number to be used hereafter was evaluated by the following equation:

$$
\mathrm{Nu}=\frac{q_{\text {net }} h}{\lambda\left(T_{w}-T_{o}\right)},
$$

where $\lambda$ is the fluid thermal conductivity, $T_{w}$ is the local heat transfer surface temperature, $T_{o}$ is the jet temperature, and $q_{\text {net }}$ is the corrected heat flux and evaluated as follows:

$$
\begin{gathered}
q_{\mathrm{net}}=\frac{Q}{S}-q_{c}, \\
q_{c}=\frac{\lambda_{p}\left(T_{w}-T_{b}\right)}{\delta},
\end{gathered}
$$

where $Q$ is the total electric power input, $S$ the total area of the heated strips, $\delta$ the thickness of the target plate, $\lambda_{p}$ the thermal conductivity of the target plate, and $T_{b}$ the back surface temperature of the target plate measured with additional 13 thermocouples attached to the back surface of the target plate itself and evaluated from the temperature measured with the 13 thermocouples.

In this experiment, the uncertainty associated with the jet exit velocity and local Nusselt number was estimated to be $4.7 \%$ and $7.8 \%$ with a $95 \%$ confidence level, respectively.

\section{Result and Discussion}

Preliminary experiment for a free jet issuing from the rectangular exit was performed. The jet velocity for the free jet was measured over the jet central axial range from the exit to $20 h$ with a hot-wire anemometer. Figure 3 shows the distributions of centerline mean velocity presented by $U_{m} / U_{o}$ and of root mean square value, $u^{\prime}$, of fluctuating velocity normalized by $U_{m}$ versus $X / h$. The results of the previous rectangular jet with aspect ratio 15 (Alnahhal and Panidis [9]) and of the two-dimensional jet (Bradbury [10]) were also shown in Figure 3 to compare them with present results. 


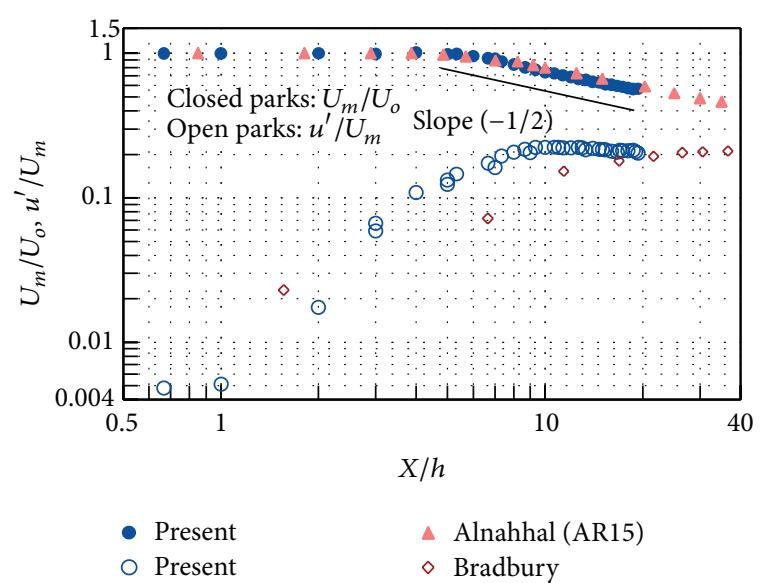

FIGURE 3: Distributions of normalized centerline mean velocity and turbulence intensity.

The jet potential core region where the values of $U_{m} / U_{o}$ are equal with approximately one is $X / h \leq 5$. The normalized centerline velocity, $U_{m} / U_{o}$, in the region of $X / h \geq 7$ decays almost proportional to minus one-half power of $X / h$, that is the jet typically have characteristics of a two-dimensional jet. On the other hand, the normalized turbulence intensity, $u^{\prime} / U_{m}$, near the jet exit is about $0.48 \%$ and their values in $X / h \geq 9$ became approximately 0.2 , that value is almost the same as the result of a two-dimension jet [10].

Normalized mean streamwise velocity, $U / U_{m}$, and turbulence intensity, $u^{\prime} / U_{m}$, along the lateral $(Y)$ and spanwise $(Z)$ directions against $2 Y / b_{y}\left(b_{y}\right.$ is the distance where the mean streamwise velocity is half of the centerline velocity at the each $X / h$ location) and $Z / h$ are presented in Figures 4(a)4(b), respectively. Solid line in Figure 4(a) is the distribution obtained by Goertler's solution for a two-dimensional jet. The mean velocity and turbulence intensity shown in Figure 4(a) are approximately uniform over the region $2 Y / b_{y} \leq|0.6|$ at $X / h=1$. In contrast, the uniform regions of the mean velocity decrease at $X / h=3,5$, and the normalized turbulence intensity, $u^{\prime} / U_{m}$, becomes the saddleback distribution and the $u^{\prime} / U_{m}$ value increases with increase of $X / h$ value. The mean velocity along $Z$ axis was almost uniform over the region $-6 \leq Z / h \leq 6$ even at $X / h=5$ in Figure $4(\mathrm{~b})$.

3.1. Flow Field Characteristics. The mean and fluctuating pressure on the target plate was measured to consider the flow field near its surface and the characteristics of the impingement heat transfer and the association with the fluctuating pressure. Figures $5(a)-5(d)$ show the distributions of time averaged pressure along $z$ axis for $H / h=2,3,4$, and 5. The $P$ is the time averaged gauge pressure measured on the target plate and the $P_{o m}$ is time averaged gauge pressure measured on the target plate at $z / h=0$ for normal impinging jet without the two confining plates. The open both sides area among the nozzle end plate, confining plates, and plate is less than or equal to the nozzle exit area only for $W / h=2.7$, 3.3 , and $H / h=2$. The $P$ values measured in the region

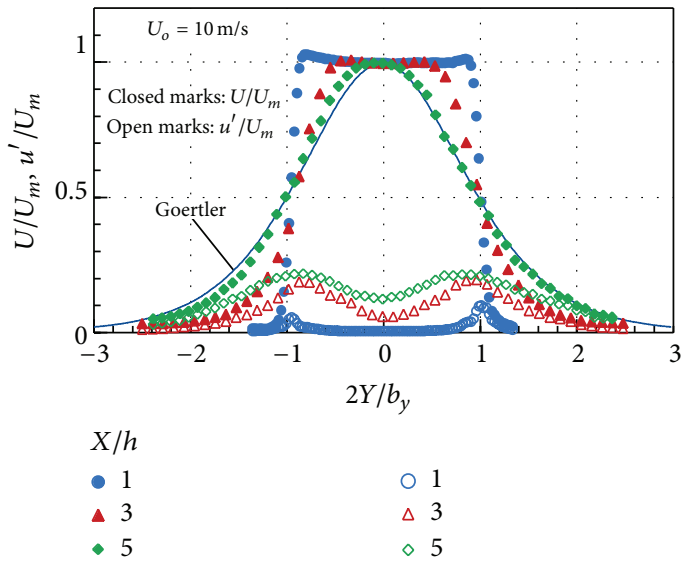

(a) Along the Yaxis

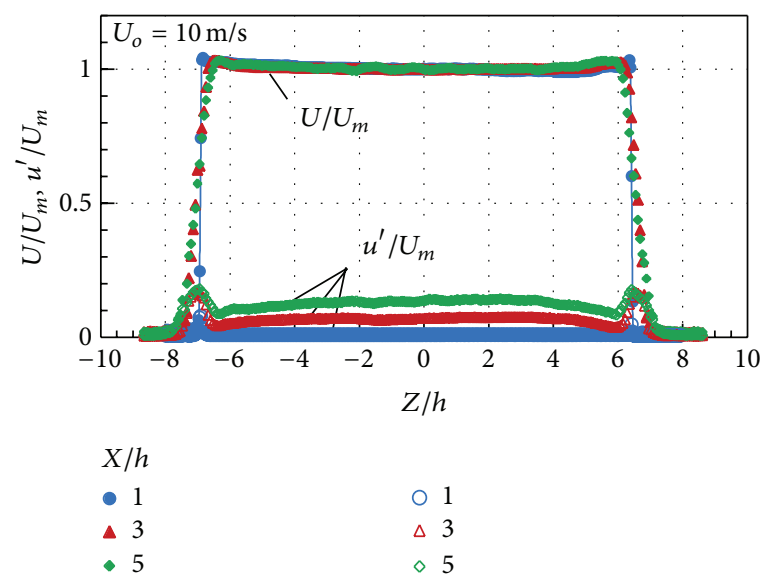

(b) Along the Zaxis

FIGURE 4: Distributions of normalized mean velocity and turbulence intensity at different downstream locations.

$-6<z / h<6$ in all cases for $H / h=2$ and 3 and two cases for $H / h=4$ and 5 with the two confining plates, however, are larger than that for the normal impinging jet. The shape of the pressure distribution with the two confining plates is probably rather convex for the top around $z / h=0$ or flat in the region $-6<z / h<6$ for $H / h=2$, 3, and 4 . In contrast, for $H / h=5$, not all the $P$ values measured for the presence of the two confining plates are larger than that for the normal impinging jet and the shape of the pressure distribution is concave for the top around $z / h=0$ for $W / h=$ 5.3. The concave shape may be due to presence of a pair of recirculation regions around the $z / h=0$. The mean pressure distributions for all cases are approximately symmetrical for $z=0$. Therefore it is thought that there are not the asymmetry characteristics of the flow on the $z$ axis.

Figures 6(a)-6(d) show the distributions of the fluctuating pressure on the target plate for $H / h=2,3,4$, and 5 . The $p^{\prime}$ shown in Figure 6 is the root mean square value of fluctuating pressure. The $p^{\prime}$ values increase in most cases owing to mounting the two confining plates. The $p^{\prime}$ values for each location of $H / h$ vary with the $W / h$ value. 

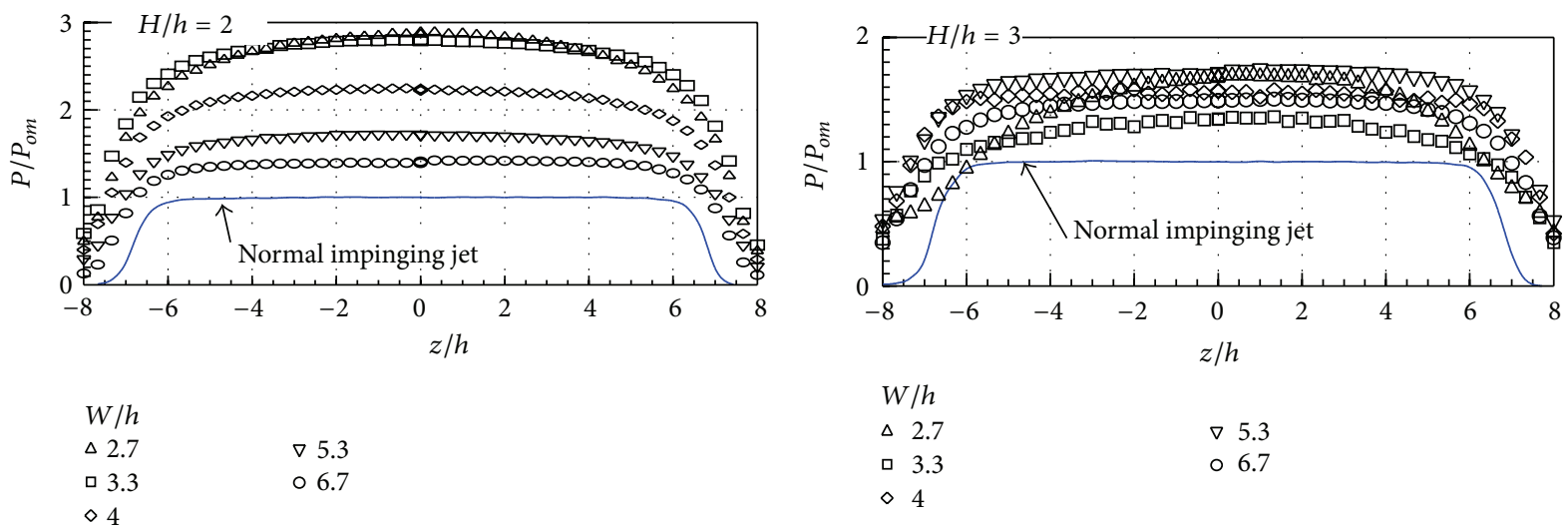
$W / h$
$\Delta 2.7$
3.3
$\diamond 4$

$\nabla 5.3$

$\circ 6.7$

(a) $H / h=2$

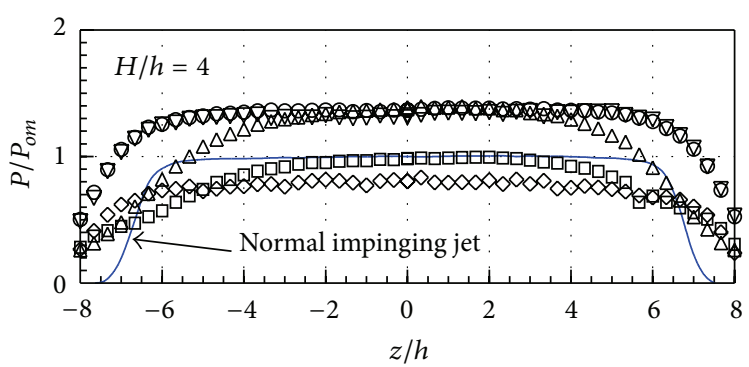

(b) $H / h=3$
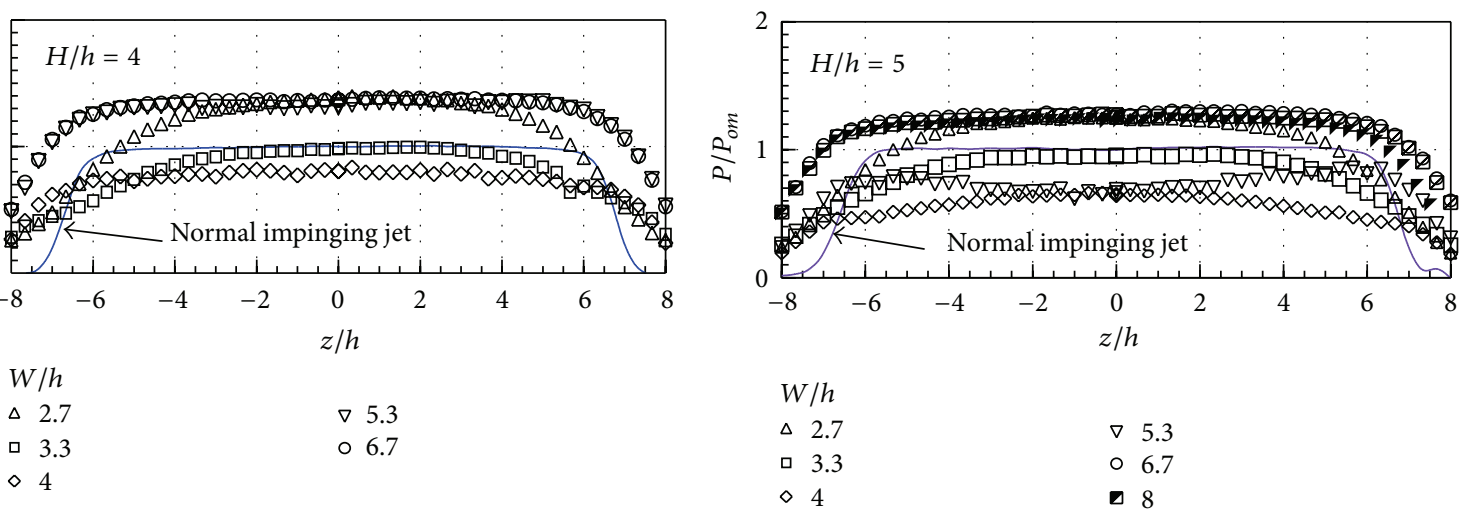

(c) $H / h=4$

(d) $H / h=5$

Figure 5: Distribution of time averaged pressure on the target plate with confining plates.

TABLE 1: Difference in flow patterns by several conditions.

\begin{tabular}{lcccc}
\hline & $H / h=2$ & $H / h=3$ & $H / h=4$ & $H / h=5$ \\
\hline$W / h=2.7$ & (b) & (a) & (a) & (a) \\
$W / h=3.3$ & (b) & (a) & (b) & (a) \\
$W / h=4$ & (b) & (b) & (b) & (a) \\
$W / h=5.3$ & (b) & (b) & (b) \\
$W / h=6.7$ & (b) & (b) & (b) \\
$W / h=8$ & & & & (b) \\
\hline
\end{tabular}

Therefore, the relation between fluctuating pressure at $z / h=0$ and the confining plate-to-plate spacing ratio is shown in Figure 7. The $p_{o o}^{\prime}$ and $p_{o}^{\prime}$ are the root mean square value of fluctuating pressure on the target plate at $z / h=$ 0 without and with the two confining plates, respectively. The $W / h$ positions of the maximum $p_{o o}^{\prime} / p_{o}^{\prime}$ value exist at each nozzle-to-target plate spacing, $H / h$, and those positions increase with an increase in the $H / h$ value.

The flow fields of the impinging jet without or with the two confining plates were qualitatively examined by means of smoke wire visualization. Figures $8(a)-8(d)$ show the instantaneous photographs taken from side view for the absence of the two confining plates with $H / h=2,3,4$, and 5 , respectively. The vortices of the jet generated near the long side of the exit were approximately symmetric for the center axis of the jet. In addition, in the case of each impinging distance, the jet issued out approximately horizontally.

Figures 9(a)-9(b) exemplify the instantaneous photographs taken from side view for presence of the two confining plates with $H / h=3$ for $W / h=3.3$ and 4 , respectively. In the case of $W / h=3.3$, the direction of the flow changed into the upper part and flowed toward the bottom after the flow impinged in the upper confining plate, and a recirculation was formed in the bottom of the region surrounded with the plates. In contrast, the flow swung up and down for the jet center surface for $W / h=4$.

Even in the case of other conditions, we can classify it into two flow patterns such as Figure 10. The flow pattern (a) is the type that the flow is inclined to either upper part or bottom 

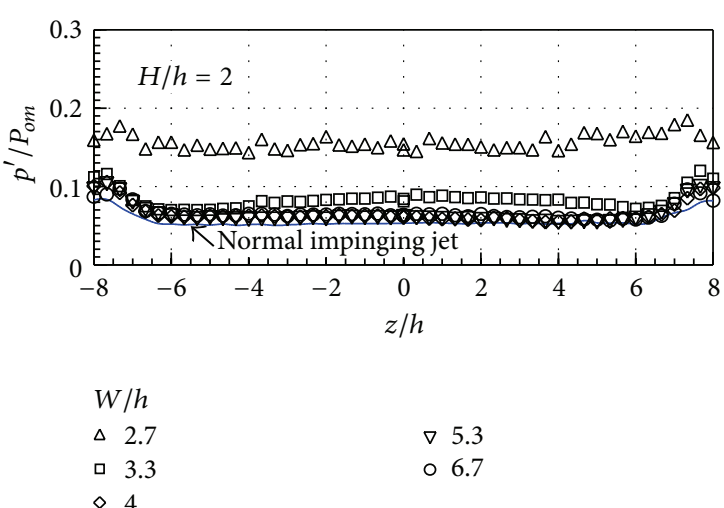

(a) $H / h=2$
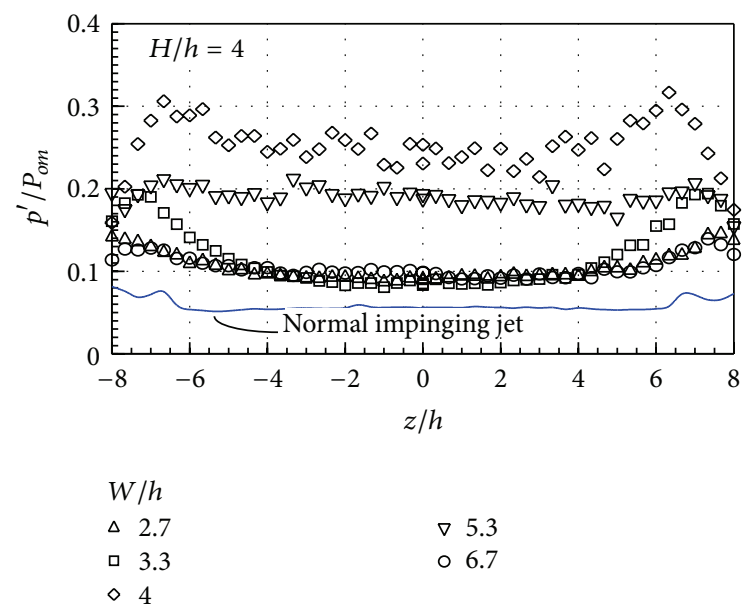

(c) $H / h=4$

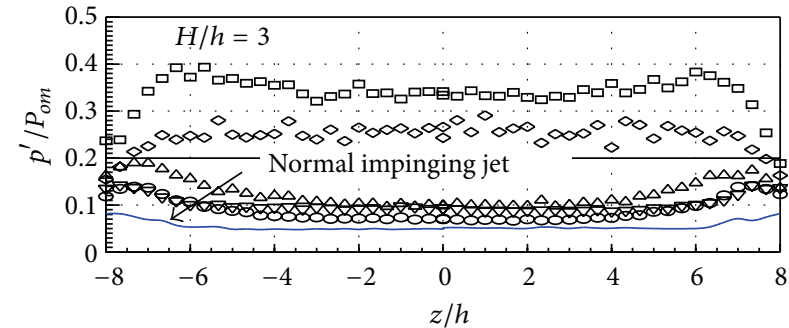

$W / h$

\begin{tabular}{|c|}
\hline$\Delta \quad 2.7$ \\
\hline ㅁ 3.3 \\
\hline
\end{tabular}

$\diamond 4$

(b) $H / h=3$
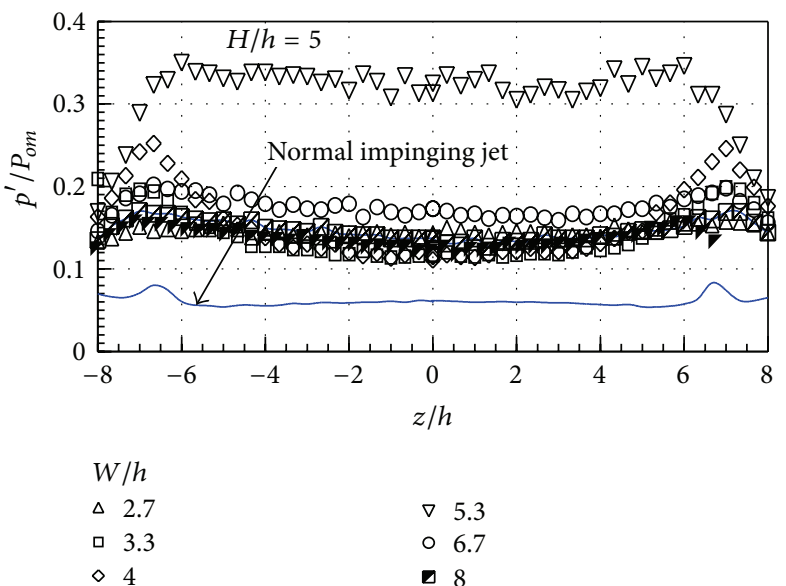

(d) $H / h=5$

FIGURE 6: Distribution of fluctuating pressure on the target plate with confining plates.

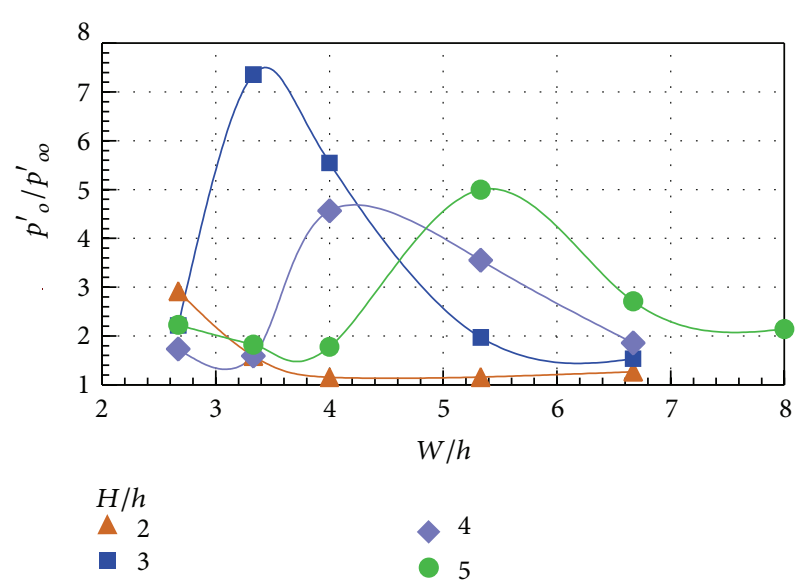

FIGURE 7: Relation between fluctuating pressure and the confining plate-to-plate distance ratio.

and the pattern (b) is the type that the jet flow swings up and down. The presence of the two confining plates mounted near the exit generated the perturbational flow field like that for using a two-dimensional suddenly expanded nozzle [11]. The differences in the flow patterns by the experiment conditions are shown in Table 1. Signs (a) and (b) in Table 1 show two kinds of flow patterns shown in Figure 10. The clear mechanisms to become two kinds of the flow patterns are not clear; however, the conditions are guessed as follows. In the cases of $W<H$, the jet is drawn to a either side of confining plate due to the Coanda effect because of smaller gap between the jet and the confining plates. Disruption of pressure balance between the upper and lower region of the jet for some reason might cause the jet incline to opposite side. In these cases it seems that the vibration of the flow along spanwise also occurs locally.

3.2. Heat Transfer Characteristics. Figure 11 shows the distributions of local Nusselt number on the target plate along $z$ axis for normal impinging jet without confining plates. For $H / h=2,3$, and 4 corresponded to a potential core region of the free jet used in the present study, the $\mathrm{Nu}$ values over the range $-6 \leq z / h \leq 6$ are closely the same. The $\mathrm{Nu}$ values for $H / h=5$ corresponded to a transition region of the free jet are almost the same as values in the case of $H / h=2,3$, and 4. For all the cases the maximum $\mathrm{Nu}$ values obtained near 


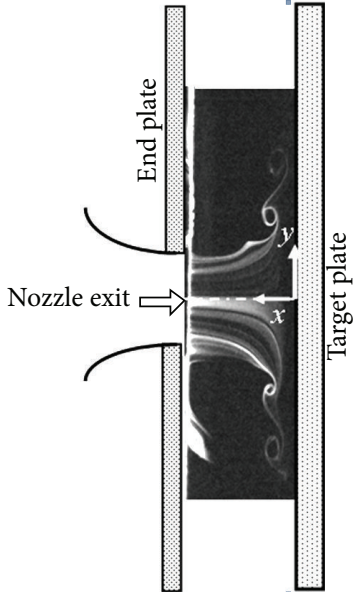

(a) $H / h=2$

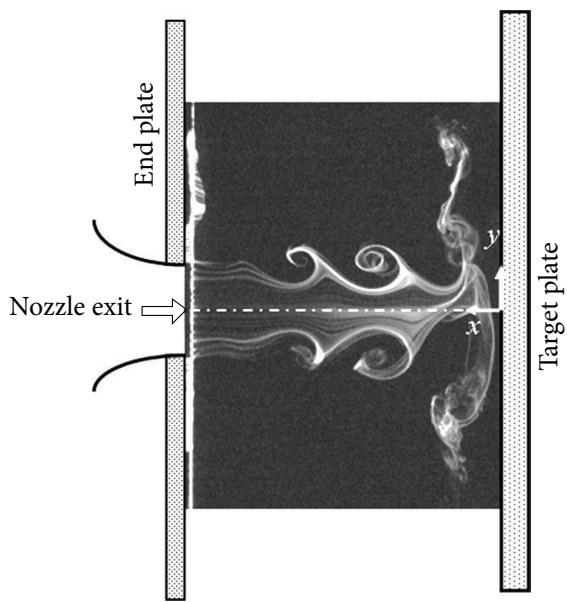

(c) $H / h=4$

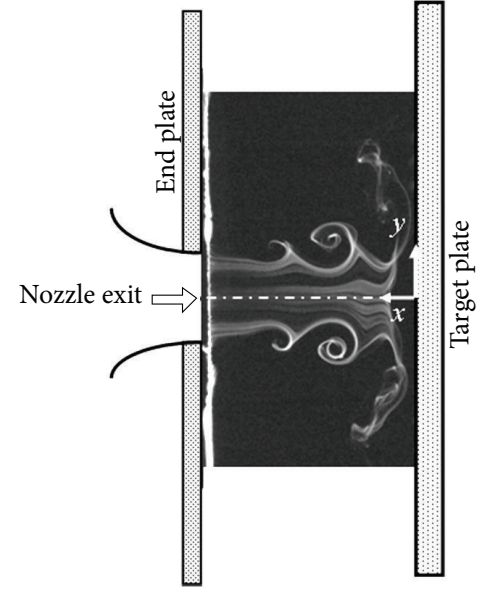

(b) $H / h=3$

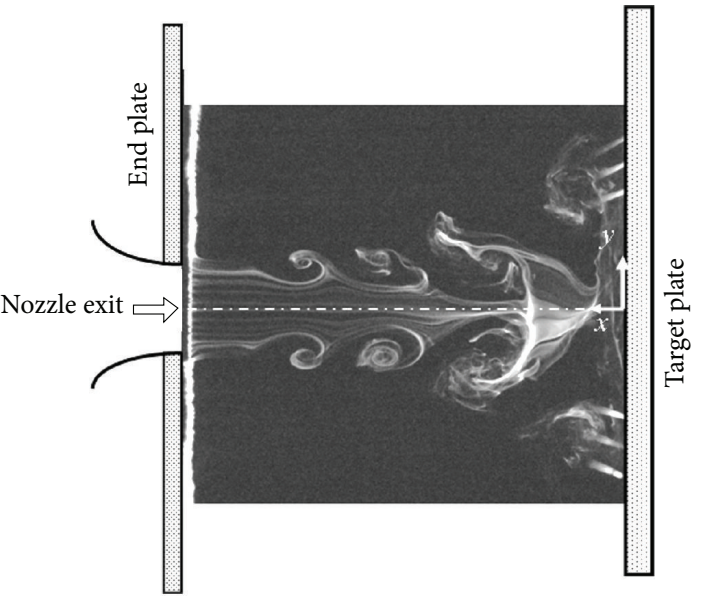

(d) $H / h=5$

Figure 8: Photographs taken from side view without confining plates.

$z / h= \pm 6.7$ resulted from that turbulent intensity measured along the $z$ axis in the preliminary study for the free jet had been maximum near the short sides of the exit. By the way, the $\mathrm{Nu}$ values at the geometric stagnation point were large about $11 \%$ compared with the results reported by Gardon and Akfirat [12]. This discrepancy may have resulted in the difference in the turbulence intensity near the exit and in the development process of the turbulence along the jet axis reported by them.

Figures 12(a)-12(d) show local Nusselt number, Nu, measured along the $z$ axis for the presence of the two confining plates at $H / h=2,3,4$, and 5 . The solid lines shown in the figures are the $\mathrm{Nu}$ values for the normal impinging jet shown in Figure 11. As the impinging jet flow passed through both open sides for the presence of the two confining plates, disappearance of the maximum $\mathrm{Nu}$ recognized near $z / h=$ \pm 6.7 for the normal impinging jet brought almost uniformity of the $\mathrm{Nu}$ values over the whole region on the target plate except some conditions. The $\mathrm{Nu}$ value over the range $-6 \leq$ $z / h \leq 6$ for the presence of the two confining plates is larger than $\mathrm{Nu}$ value for normal impinging jet.
Figure 13 shows the relation between the enhancement ratios of the $\mathrm{Nu}$ values obtained at the geometric stagnation point and $W / h$ values. $\overline{\mathrm{Nu}}_{o o}$ and $\mathrm{Nu}_{o}$ are the mean values measured two or three times at $z / h=0$ for the normal impinging jet and local Nusselt number at $z / h=0$ for the presence of the two confining plates, respectively. Maximum enhancement ratio of local Nusselt number achieved here is about $50 \%$ for $H / h=3$ and 4 . The enhancement of local Nusselt number obtained here probably results from the swing-type flow shown in Figure 10. The difference in heat transfer enhancement ratio seems to depend on the difference in the oscillation frequency of the swing-type flow when we take the visualization result of the flow into consideration. Haneda et al. [13, 14], Fu et al. [15-17], Lin et al. [18], and Chaniotis et al. [19] have reported impinging jet heat transfer enhanced owing to oscillating flow. The $W / h$ values that obtained maxima of $\mathrm{Nu}_{o} / \overline{\mathrm{Nu}}_{o o}$ for each $H / h$ value are different from the $W / h$ values that obtained maxima of $p_{o o}^{\prime} / p_{o}^{\prime}$. Narayanan et al. [20] and Gao and Ewing [4] have also reported that peak fluctuating wall pressure disagreed with 


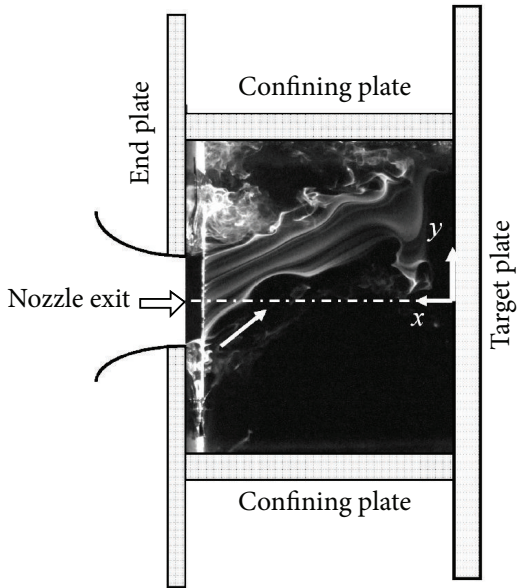

Smoke wire method

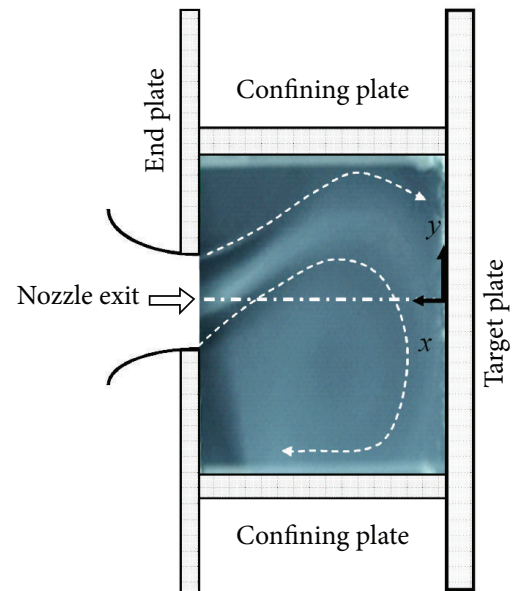

Smoke method

(a) $W / h=3.3$

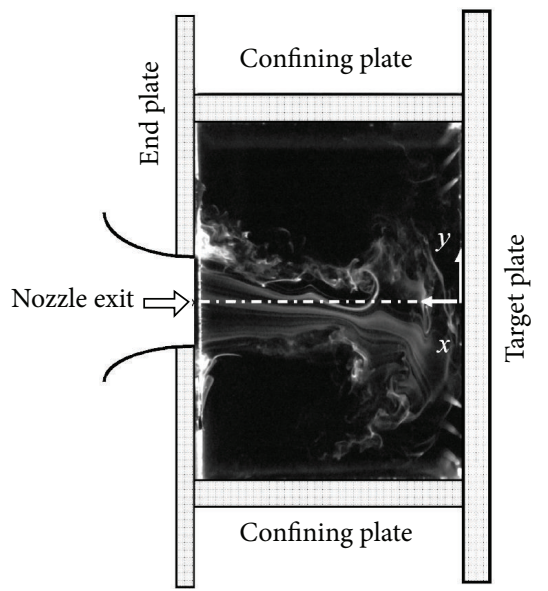

Smoke wire method

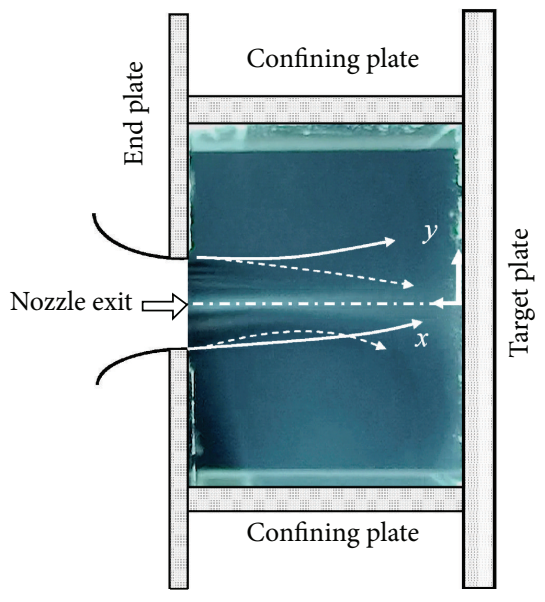

Smoke method

(b) $W / h=4$

Figure 9: Photographs taken from side view for $H / h=3$ with confining plates.

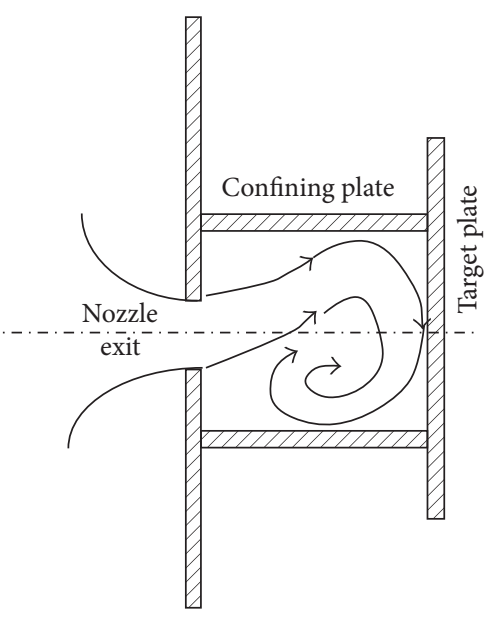

(a) Inclined-type flow

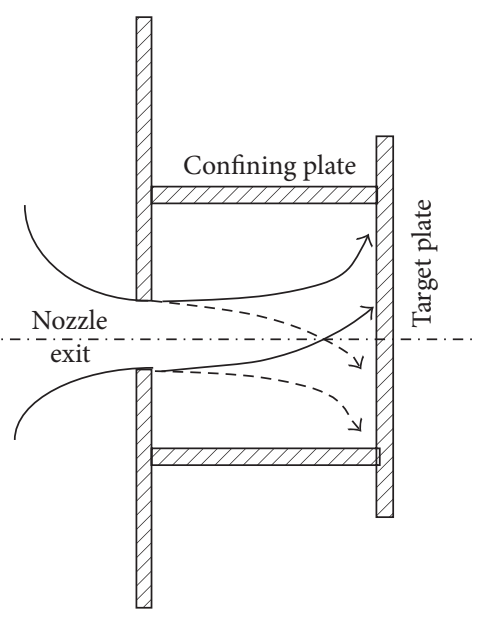

(b) Swing-type flow

FIGURE 10: Flow patterns obtained by the all experimental conditions. 

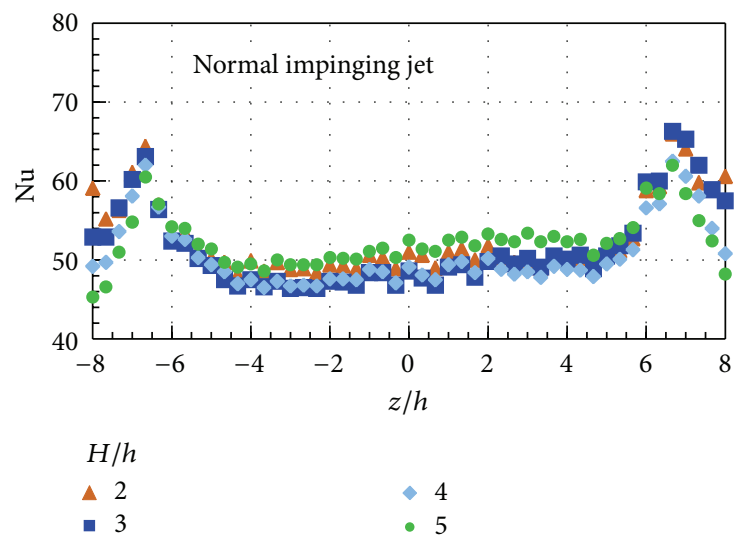

FIGURE 11: Distribution of local Nusselt number for the normal impinging jet.

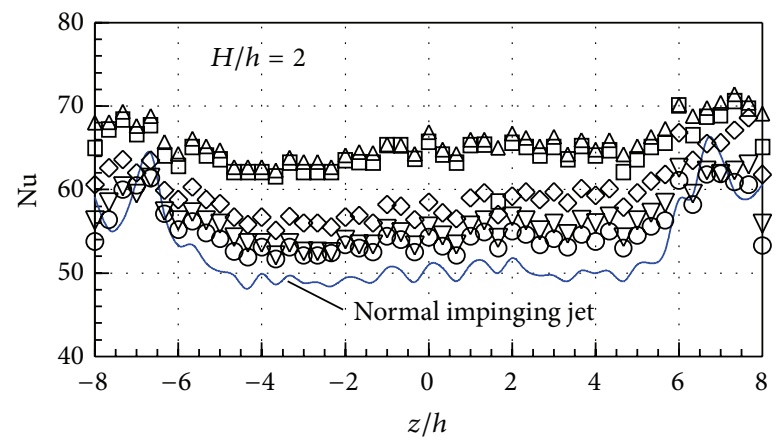

$W / h$

$\Delta 2.7$

3.3

$\diamond 4$

(a) $H / h=2$

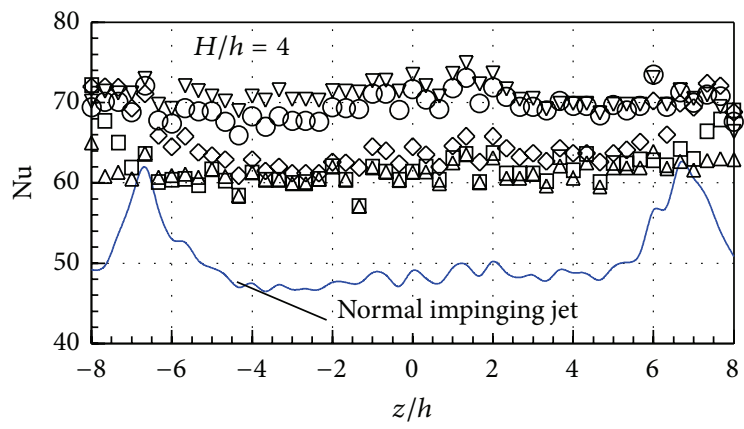

$W / h$

$\Delta 2.7$

口 3.3

$\diamond 4$

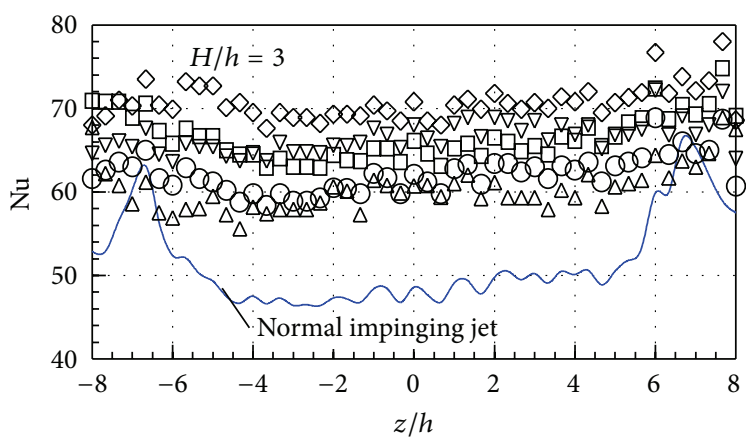

$W / h$

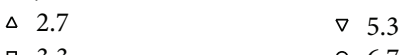

ㅁ 3.3

$\diamond 4$

(b) $H / h=3$

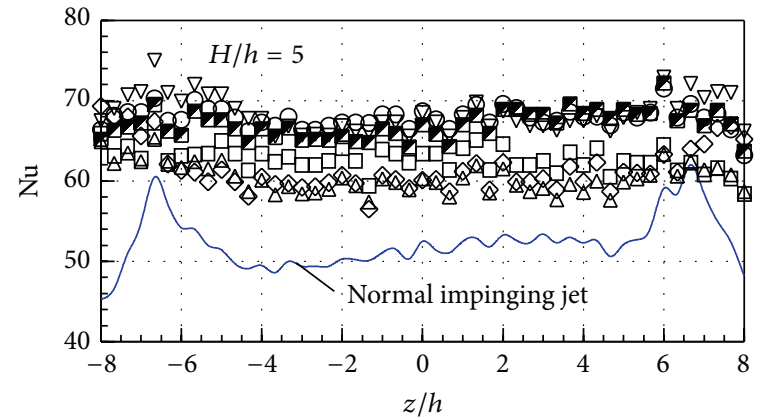

$W / h$

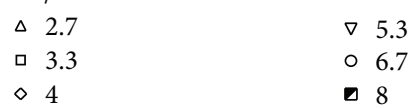

(d) $H / h=5$ (c) $H / h=4$

$\nabla 5.3$

○ 6.7

FIGURE 12: Distribution of local Nusselt number for presence of confining plates.

the peak in an impinging jet heat transfer except stagnation region.

Finally, the enhancement of spatial mean Nusselt number averaged over the region $-8 \leq z / h \leq 8$ is shown in Figure 14. $\overline{\mathrm{Nu}}_{m o}$ and $\mathrm{Nu}_{m}$ are the arithmetic mean value of the spatial mean Nusselt number calculated from $\mathrm{Nu}$ values measured two or three times for normal impinging jet and the spatial mean Nusselt number for the presence of the two confining plates, respectively. The spatial mean Nusselt number is enhanced by installing the two confining plates in all cases. The maximum enhancement of mean Nusselt number increased by about $40 \%$ for $W / h=5.3$ and $H / h=$ 


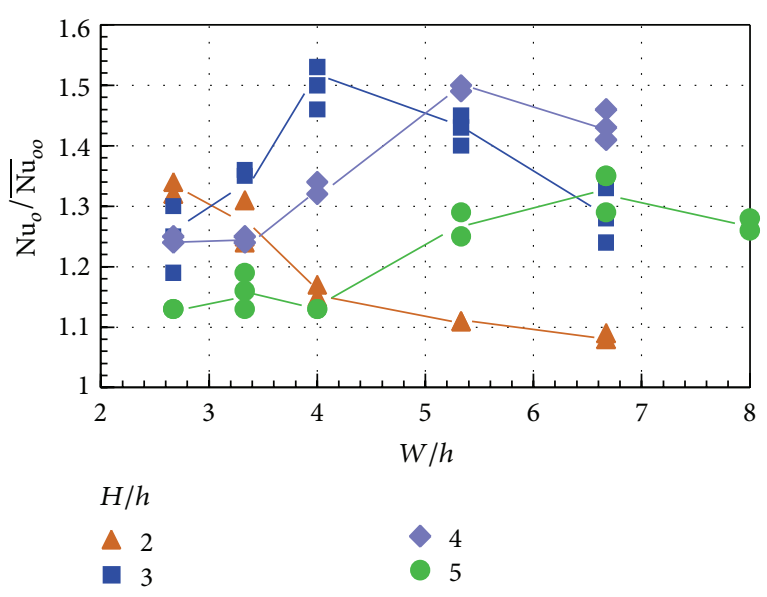

Figure 13: Enhancement of local Nusselt number at $Z / h=0$.

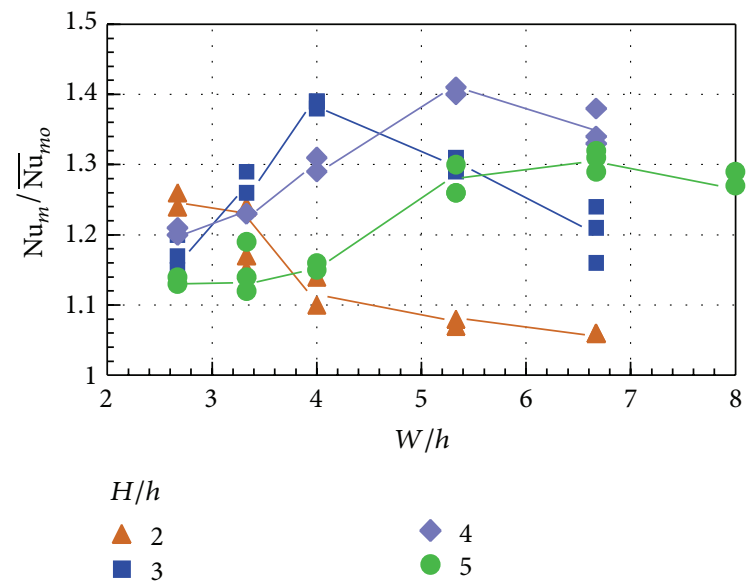

FIGURE 14: Enhancement of spatial mean Nusselt number $(-8 \leq$ $z / h \leq 8)$.

4. Thus, the presence of the two confining plates mounted near the exit is effective to improve the spatial mean Nusselt number as well as local Nusselt number.

\section{Conclusion}

The aim of this study is to investigate the effect of the confining plates mounted in parallel with long sides of a rectangular nozzle on the flow field and impinging jet heat transfer. Mean and fluctuating pressure and heat transfer on a target plate were measured for several kinds of spacing between two confining plates at each impinging plate distance and the flow field was visualized with a smoke wire method and a smoke method. Time averaged pressure and fluctuating pressure on the surface of the target plate varied with the spacing between the two confining plates and became large owing to the presence of the two confining plates.

The result of flow visualization showed two kinds of flow patterns; one was a declined flow type and another was a swing-type flow for the presence of the two confining plates. This complicated flow enhanced the heat transfer on the target plate and brought almost uniform local Nusselt number over the whole region on the target plate. The enhancement ratio of local Nusselt number and spatial mean Nusselt number for the presence of the two confining plates are about $50 \%$ and $40 \%$, respectively.

\section{Nomenclature}

$b_{y}$ : Jet half-velocity width along lateral coordinate $(\mathrm{mm})$

$H$ : $\quad$ Distance between nozzle end plate and target plate $(\mathrm{mm})$

$h$ : $\quad$ Jet nozzle width $(\mathrm{mm})$

$\mathrm{Nu}$ : Local Nusselt number on the target plate

$\mathrm{Nu}_{m}$ : Spatial mean Nusselt number of $\mathrm{Nu}$ with confining plates

$\overline{\mathrm{Nu}}_{m o}$ : Arithmetic mean value of spatial mean Nusselt number of $\mathrm{Nu}$

$\mathrm{Nu}_{o}$ : Local Nusselt number at the origin with confining plates

$\overline{\mathrm{Nu}}_{o o}$ : Arithmetic mean value at the origin without confining plates

$P: \quad$ Time averaged gauge pressure on the surface of target plate $(\mathrm{Pa})$

$P_{\text {om }}$ : Time averaged gauge pressure on the surface of target plate at the origin without confining plates $(\mathrm{Pa})$

$P^{\prime}$ : $\quad$ RMS value of fluctuating pressure on the surface of target plate $(\mathrm{Pa})$

$p_{0}^{\prime}$ : $\quad$ RMS value of fluctuating pressure on the surface of target plate at the origin with confining plates $(\mathrm{Pa})$

$p_{o o}^{\prime}$ : $\quad$ RMS value of fluctuating pressure on the surface of target plate at the origin without confining plates $(\mathrm{Pa})$

Q: $\quad$ Total electric power (W)

$q_{c}$ : Conductive heat loss per unit area toward the back surface of target plate $\left(\mathrm{W} / \mathrm{m}^{2}\right)$

$q_{\text {net }}: \quad$ Corrected heat flux $\left(\mathrm{W} / \mathrm{m}^{2}\right)$

Re: Reynolds number based on the jet exit velocity, $h$ and $v$

S: $\quad$ Area of heated strip $\left(\mathrm{m}^{2}\right)$

$T_{b}$ : Temperature on the rear surface of target plate $(\mathrm{K})$

$T_{w}: \quad$ Temperature on the surface of heated strip (K)

$U: \quad$ Jet mean streamwise velocity $(\mathrm{m} / \mathrm{s})$

$U_{m}$ : Jet mean streamwise velocity on $X$ axis $(\mathrm{m} / \mathrm{s})$

$U_{o}: \quad$ Exit mean centerline velocity $(\mathrm{m} / \mathrm{s})$

$u^{\prime}$ : $\quad$ RMS value of velocity fluctuation $(\mathrm{m} / \mathrm{s})$

$W: \quad$ Distance between confining plates $(\mathrm{mm})$

$X$ : Axial coordinate from the center of jet exit $(\mathrm{mm})$ 
$x$ : Axial coordinate from geometrical stagnation point on target plate $(\mathrm{mm})$

$Y$ : Lateral coordinate for free jet ( $\mathrm{mm})$

$y$ : Lateral coordinate on the target plate (mm)

$Z$ : Spanwise coordinate for free jet $(\mathrm{mm})$

$z$ : Spanwise coordinate on the target plate (mm)

$\delta: \quad$ Thickness of target plate $(\mathrm{mm})$

$\lambda$ : Thermal conductivity of air $(\mathrm{W} / \mathrm{mK})$

$\lambda_{p}$ : Thermal conductivity of target plate $(\mathrm{W} / \mathrm{mK})$

$v$ : Kinematic viscosity of $\operatorname{air}\left(\mathrm{m}^{2} / \mathrm{s}\right)$.

\section{Conflict of Interests}

The authors declare that there is no conflict of interests regarding the publication of this paper.

\section{References}

[1] R. C. Deo, G. J. Nathan, and J. Mi, "Comparison of turbulent jets issuing from rectangular nozzles with and without sidewalls," Experimental Thermal and Fluid Science, vol. 32, no. 2, pp. 596606, 2007.

[2] J. San, C. Huang, and M. Shu, "Impingement cooling of a confined circular air jet," International Journal of Heat and Mass Transfer, vol. 40, no. 6, pp. 1355-1364, 1997.

[3] Z. H. Lin, Y. J. Chou, and Y. H. Hung, "Heat transfer behaviors of a confined slot jet impingement," International Journal of Heat and Mass Transfer, vol. 40, no. 5, pp. 1095-1107, 1997.

[4] N. Gao and D. Ewing, "Investigation of the effect of confinement on the heat transfer to round impinging jets exiting a long pipe," International Journal of Heat and Fluid Flow, vol. 27, no. 1, pp. 33-41, 2006.

[5] J. A. Fitzgerald and S. V. Garimella, "A study of the flow field of a confined and submerged impinging jet," International Journal of Heat and Mass Transfer, vol. 41, no. 8-9, pp. 1025-1034, 1998.

[6] M. Fenot, J.-J. Vullierme, and E. Dorignac, "Local heat transfer due to several configurations of circular air jets impinging on a flat plate with and without semi-confinement," International Journal of Thermal Sciences, vol. 44, no. 7, pp. 665-675, 2005.

[7] J. San and W. Shiao, "Effects of jet plate size and plate spacing on the stagnation Nusselt number for a confined circular air jet impinging on a flat surface," International Journal of Heat and Mass Transfer, vol. 49, no. 19-20, pp. 3477-3486, 2006.

[8] J. San, Y. Tsou, and Z. Chen, "Impingement heat transfer of staggered arrays of air jets confined in a channel," International Journal of Heat and Mass Transfer, vol. 50, no. 19-20, pp. 37183727, 2007.

[9] M. Alnahhal and T. Panidis, "The effect of sidewalls on rectangular jets," Experimental Thermal and Fluid Science, vol. 33, no. 5, pp. 838-851, 2009.

[10] L. J. S. Bradbury, "The structure of a self-preserving turbulent plane jet," Journal of Fluid Mechanics, vol. 23, part 1, pp. 31-64, 1965.

[11] S. Göppert, T. Gürtler, H. Mocikat, and H. Herwig, "Heat transfer under a precessing jet: effects of unsteady jet impingement," International Journal of Heat and Mass Transfer, vol. 47, no. 1213, pp. 2795-2806, 2004.
[12] R. Gardon and J. C. Akfirat, "Heat transfer characteristics of impinging two-dimensional air jet," ASME: Journal of Heat Transfer, vol. 88, pp. 101-108, 1966.

[13] Y. Haneda, Y. Tsuchiya, K. Nakabe, and K. Suzuki, "Enhancement of impinging jet heat transfer by making use of mechanofluid interactive flow oscillation," International Journal of Heat and Fluid Flow, vol. 19, no. 2, pp. 115-124, 1998.

[14] Y. Haneda, Y. Tsuchiya, H. Kurasawa, K. Nakabe, and K. Suzuki, "Flow field and heat transfer of a two-dimensional impinging jet disturbed by an elastically suspended circular cylinder," Heat Transfer-Asian Research, vol. 30, no. 4, pp. 313-330, 2001.

[15] W. Fu, K. Wang, and W. Ke, "An investigation of block moving back and forth on a heat plate under a slot jet," International Journal of Heat and Mass Transfer, vol. 44, no. 14, pp. 2621-2631, 2001.

[16] W.-S. Fu and K.-N. Wang, "An investigation of a block moving back and forth on a heat plate under a slot jet. Part II (the effects of block moving distance and vacant distance)," International Journal of Heat and Mass Transfer, vol. 44, no. 24, pp. 46494665, 2001.

[17] W. Fu, C. Tseng, C. Huang, and K. Wang, "An experimental investigation of a block moving back and forth on a heat plate under a slot jet," International Journal of Heat and Mass Transfer, vol. 50, no. 15-16, pp. 3224-3233, 2007.

[18] Y. Lin, M. Hsu, and C. Hsieh, "Enhancement of the convective heat transfer for a reciprocating impinging jet flow," International Communications in Heat and Mass Transfer, vol. 30, no. 6, pp. 825-834, 2003.

[19] A. K. Chaniotis, D. Poulikakos, and Y. Ventikos, "Dual pulsating or steady slot jet cooling of a constant heat flux surface," ASME: Journal of Heat Transfer, vol. 125, no. 4, pp. 575-586, 2003.

[20] V. Narayanan, J. Seyed-Yagoobi, and R. H. Page, "An experimental study of fluid mechanics and heat transfer in an impinging slot jet flow," International Journal of Heat and Mass Transfer, vol. 47, no. 8-9, pp. 1827-1845, 2004. 

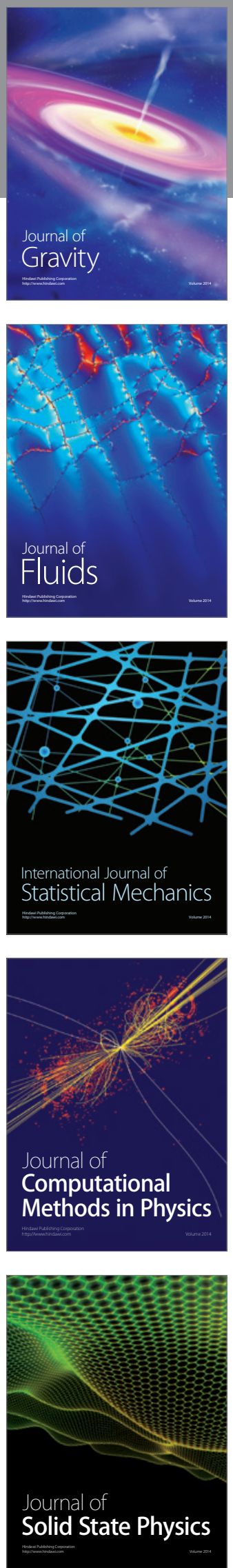

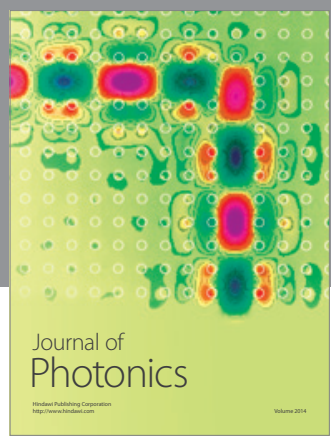

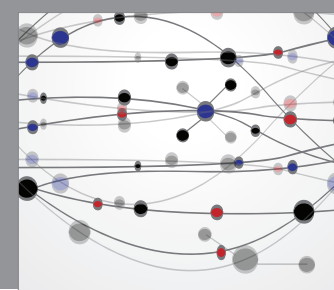

The Scientific World Journal

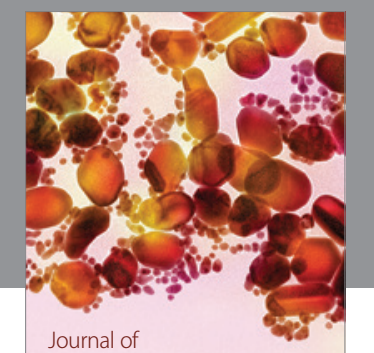

Soft Matter
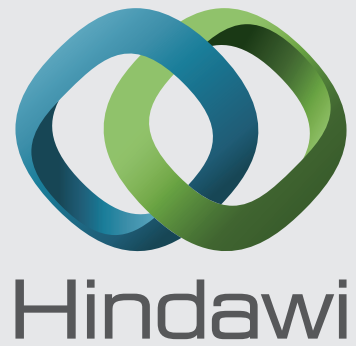

Submit your manuscripts at

http://www.hindawi.com
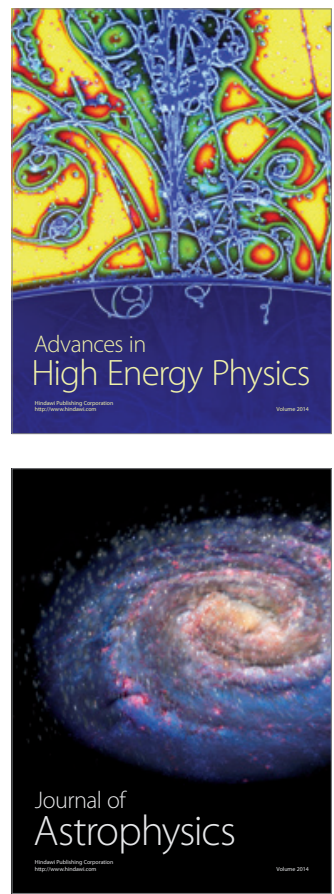
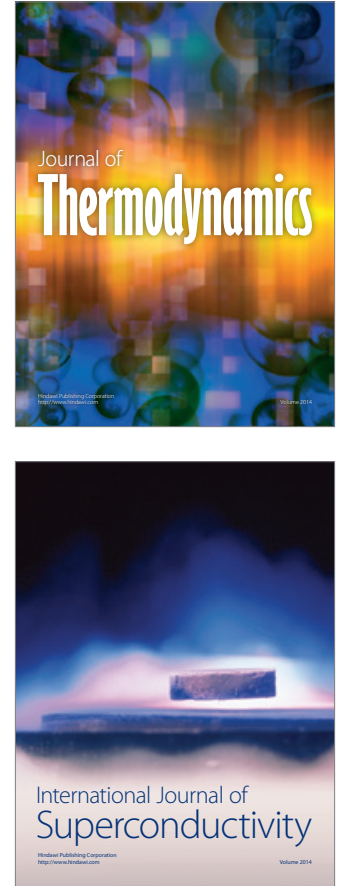
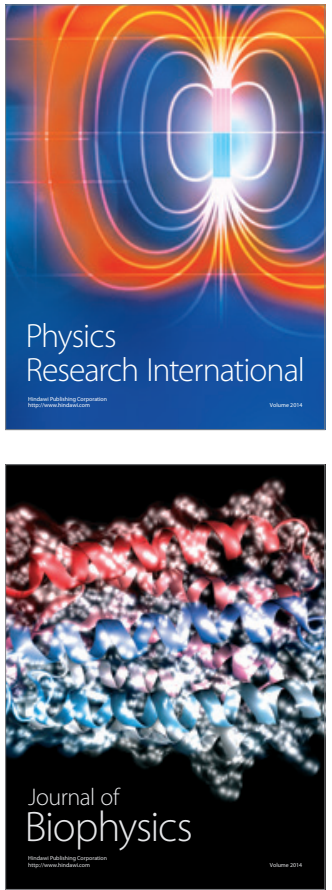
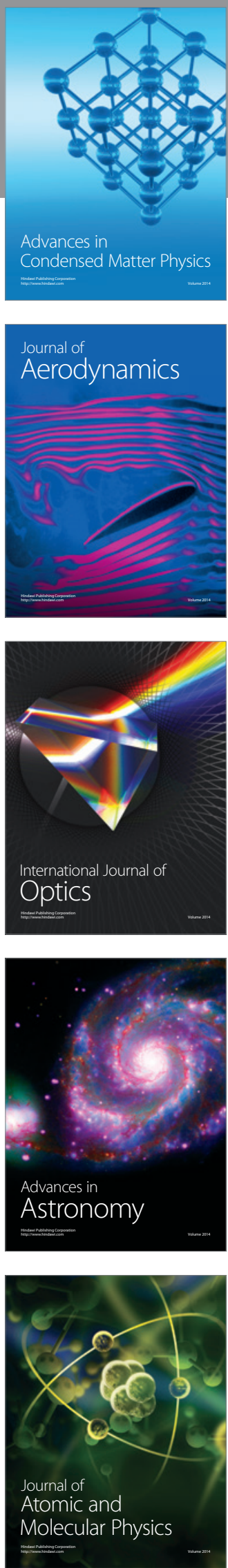